\title{
'UNTHINKABLE COMPLEXITY': ART EDUCATION IN THE NETWORK SOCIETY
}

\author{
Robert Wilson Sweeny ${ }^{1}$ \\ Indiana University of Pennsylvania
}

\begin{abstract}
"The matrix has its roots in primitive arcade games," said the voice-over, " in early graphics programs and military experimentation with cranial jacks." On the Sony, a two-dimensional space war faded behind a forest of mathematically generated ferns, demonstrating the spacial [sic] possibilities of logarithmic spirals: cold blue military footage burned through, lab animals wired into test systems, helmets feeding into fire control circuits of tanks and war planes.

"Cyberspace. A consensual hallucination experienced daily by billions of legitimate operators, in every nation, by children being taught mathematical concepts ... A graphic representation of data abstracted from the banks of every computer in the human system. Unthinkable complexity. Lines of light ranged in the nonspace of the mind, clusters and constellations of data. Like city lights, receding ..." (Gibson, 1984, p. 51).
\end{abstract}

The 'cyberspace' that science fiction author William Gibson envisioned in the early 1980's has influenced many aspects of contemporary life, as individuals, groups, and institutions make complex connections, creating elaborate personal, social and technological networks. The Internet is possibly the most intricate of these networks -- linking large portions of the world's population, allowing them to communicate, share ideas, buy and sell goods, and explore terrains previously unimagined. This process of exploration -- this unique interlinking of individuals, beliefs, and societies -- represents both the exhilaration of newfound friendship, acquired knowledge and new ways of seeing, as well as the danger of power unchecked, the impulse to colonize that creates connections so dense that one must adapt or become immobilized.

These are territories that have yet to be explored within the field of art education in general. An exploration of issues related to these sociotechnical networks might result in the development of approaches to curriculum and practice that respond to these structures -- a process that becomes all the more relevant as art educational spaces become increasingly 
intertwined with cyberspaces, and as daily life becomes networked. An acknowledgement of these connections might result in art educational practice that is socially relevant and critically oriented, that addresses the potential for the actual within the metaphors that concern the virtual.

William Gibson's Neuromancer (1984) presents images of a bleak, dystopian future society that resembles aspects of our own - save for the advancements in biomedical technology that allow for rampant cloning and techno-human interfaces, simulating human senses and selves. These bodily adaptations are paired with digital experiences that combine aspects of the physical world with the virtuality of data: cyberspace. Gibson's term 'cyberspace' is now commonly used to describe the connections that make up and take place on the Internet: the contemporary networks of physical infrastructure and ephemeral interactions that include the text and image oriented webpages of the World Wide Web, the communication-based interactions of email and Instant Messenger, and the recent diaristic weblog (blog) phenomenon.

His descriptions of futuristic networked interactions have been equally influential in works of literature, popular movies, and video games - writing of a geometric cyberspace that reflects the utopian principles of high modernism, while helping to glamorize the activities of computer hackers that critique such structures (Bukatman, 2000). These highly influential fictions have helped to shape the language and perception of simulated interactions that take place on the Internet, affecting numerous aspects of contemporary life - not only those that rely upon digital technologies. These are interactions that have resulted in what sociologist Manuel Castells (1996) terms the 'network society.'

Simulation is central to life in the network society. As sociologist Sherry Turkle proposes in her landmark study of online identity titled Life on the Screen (1995), one of the primary results of increased online interaction can be seen in the 'culture of simulation,' contributing to a

\footnotetext{
1 The author welcomes comments or questions, and can be reached at: College Of Fine Arts, 110 Sprowls Hall, Indiana University of Pennsylvania, Indiana, PA 15705, or online at bob@untwine.net
} 
contemporary sense of self, identity, and community that is a synthesis of physical and virtual experiences. Online simulations hold the power to reproduce these experiences, to create alternate realities that allow for reflection and reconnection, much like the battle simulations described in the preceding quote, and contemporary video games such as SimCity. Simulations allow for new experiences with actual spaces, specific individuals and tangible objects -- they transport the reader, the participant, the combatant to another space, to imagine what might be from what is. They make connections between worlds, allow us to look anew at situations taken for granted, and remind us of the threads that both unify and bind. They offer the possibility for critical reflection and creative response in the network society.

Manuel Castells' concept of the network society has informed much of the research that I have undertaken as a student in the Doctoral program in Art Education at Penn State University. My dissertation consists of analyses of student work related to Internet use, created in the general education art course titled Art 100: Concepts and Creations in the Visual Arts. In order to explore the possibility of modes of critique in these projects that were specific to the Internet, I analyzed my examples using a variety of theoretical sources. My primary theories were drawn from Castells (1996, 1999), who discusses the contemporary socioeconomic impact of technological networks in his three-part study titled The Rise of the Network Society. In order to provide historical context, and to address the social and aesthetic impact of digital technologies, I relied upon Walter Benjamin's The Work of Art in the Age of Mechanical Reproduction (1968). Finally, to provide a framework for an analysis of these projects as forms of critique, I turned to Michel de Certeau's The Practice of Everyday Life (1984). Each of these theories allowed me to explore the critical aspects of student work related to Internet use, pointing towards possibilities for art educational practice that responds substantially to and participates critically within a network society.

In this paper I will discuss the possibilities for art educational practice within the network society. This is a process that may provide for a better understanding of contemporary life - 
specifically lives lived within complex networks of images. As I will suggest, the simulation of images in the network society challenges art historical notions of authenticity, authorship, and authority, and that point towards new forms of visuality. This analysis of simulated images is necessary for an expansive, socially relevant discussion of visual culture within the field of art education.

I will begin this discussion of my research with an overview of Castells' (1996) description of the network society. I will then describe how the challenges associated with the digital simulation of images relate to the theories of mechanical reproduction discussed by Walter Benjamin (1968), followed by an analysis of Michel de Certeau's (1984) notion of the tactic. I will then discuss current networked artistic activities that represent a contemporary understanding of the critical potential of the network, representing what I will term a 'network aesthetic.' I will conclude with a discussion of the implications for network aesthetics and tactics in art educational practice.

\section{Everyday Life and Visual Culture in the Network Society}

The networks formed between individuals and machines during our current information age have affected large portions of the world's population, forcing change at a variety of levels, while simultaneously representing an outgrowth of these changes. Information technologies have created what Manuel Castells (1996) calls the 'network society.' Electronic networks encompassing the Earth are changing global economies, national boundaries, and personal identities, changing once static forms of power and trade: "Our societies are primarily made of flows exchanged through networks of organizations and institutions" (1999, p. 57). The Internet allows for these exchanges, and is simultaneously a direct result of it. It is an evolving space, constantly shifting its boundaries, incorporating new information while rendering other data obsolete. While the Internet is affecting change on a massive scale, it also is affecting individuals 
who interact and intervene in this space. As Castells states, in The Rise of the Network Society (1996):

People, institutions, companies, and society at large transform technology, any technology, by appropriating it, by modifying it, by experimenting with it. This is the fundamental lesson from the social history of technology, and this is even more so in the case of the Internet, a technology of communication. Conscious communication (human language) is what makes the biological specificity of the human species. Since our practice is based on communication, and the Internet transforms the way in which we communicate, our lives are deeply affected by this new communication technology. On the other hand, by doing many things with the Internet, we transform the Internet itself. A new socio-technical pattern emerges from this interaction ( $p$ 4-5).

Castells therefore identifies the fundamental changes associated with the networked technologies of the Internet - changes that register at the larger social and cultural levels as well as those of the individual, within the space of everyday life. The current interest in visual culture approaches in the field of Art Education references forms of communication that are based in similar aspects of society, informed by the "aesthetics of everyday life" (Duncum, 2002a). Many art educators have written on the possibilities for pedagogy that reference 'everyday' aesthetic sources such as professional wrestling (Duncum, 2002b), television shows (Freedman and Schuler, 2002), and shopping centers (Stokrocki, 2002). These sources are typically presented as objects to be consumed, as images that act upon the viewer, rather than forms of communication that allow for expression and transformation. As Duncum (2002a) states: "Everyday life involves the mundane world, which is seemingly unaffected by great events and the extraordinary. It involves the reproduction and maintenance of life, not the production of new ways of thinking and acting" (p. 4). Central to this argument is the assumption that individuals typically young people - are not participating in critical activity when they interact within the spaces of visual culture. This is a point that I have questioned through the examples from Art 100 , examples that represent new forms of response and critique related to developing technologies such as the Internet. 
The space of everyday interactions in the network society is much different as described by Castells (1996). An element of this social structure, the Internet is a dynamic, constantly evolving space that allows individuals to transform their lives as they are simultaneously transformed through their interactions. As is probably readily apparent to most art educators, visual images play a large role in these transformations. However, within the network society it is important to consider what images represent as well as how they are represented, a critical approach undertaken by Walter Benjamin in his influential essay The Work of Art in the Age of Mechanical Reproduction (1968).

As Walter Benjamin (1968) has provocatively and popularly suggested, mechanically reproduced images are much different from their art historical counterparts, in both their formal attributes and their social functions. He suggested that when works of art are mechanically reproduced they lose their 'aura,' an attribute related to both the ritual use of artifacts and the social function of fine art. The destruction of aura results in a social shift - works of art are no longer valued for their formal qualities, but for their uniqueness, their originality. Benjamin sees the potential for the mechanically reproduced work - specifically photography and film - to undermine the authority of the artist, and possibly the power of the 'Fuhrer cult' in Weimar republic Germany.

The revolutionary potential for photography and film failed to come to fruition as Benjamin predicted. His theories may be applicable to our current are, however, influenced less by mechanical reproduction than by digital simulation. The shifts between the traditional and the mechanical described by Benjamin are multiplied when images are simulated through the operations of digital networks. The possibilities for the digital image to challenge concepts of authenticity, authorship, and authority can be seen in many examples that I have analyzed in my research, from student works in Art 100 to online projects by contemporary artists such as Vuk Cosic, Stelarc, and Mariko Mori, to acts of social resistance by collectives such as The Surveillance Camera Players. If we take into account the technologies that contribute to the cumulative 
meaning of images - both how they are consumed and produced in art educational spaces -- art educators might find the opportunity to address and critique the notion of visuality as it is operates within a culture of simulation.

As theorist Nicholas Mirzoeff (1998) proposes, the notion of visual culture is not so much based in the presence of more images than at previous times in history, but rather the contemporary social impulse to represent information in a visual manner. He writes:

Visual culture does not depend on pictures but on [the] modern tendency to picture or visualize existence. . . . One of the key tasks of visual culture is to understand how these complex pictures come together. They are not created from one medium or in one place, as the overly precise divisions of academia would have it. Visual culture directs our attention away from structured, formal viewings like the cinema and art gallery to the centrality of visual experience in everyday life (Mirzoeff, 1998, p. 7).

This is a shift that has been amplified through the operations of modern computer systems that allow for both the increased reception of these images as well as their production. In his conceptualization of visual culture, Mirzoeff addresses the issue of image production -- 'how these complex pictures come together.' This issue is typically not addressed in discussions of visual culture within the field of Art Education, where students (and teachers) are typically described as being inundated by images, or at best passive consumers of images. The 'everyday life' to which Duncum (2002a) refers is much different that the one described by Mirzoeff. This 'everyday life' is one that sees individuals as both producers and consumers, in a manner similar to Castells (1996). These are forms of active production that blur the relationship between not only academic divisions, but between forms of critique and creation. Historian and ethnologist Michel de Certeau outlines a variety of 'tactics' that demonstrate the idiosyncratic modifications made by individuals within capitalist societies in his book The Practice of Everyday Life (1984).

Certeau is primarily interested in studying a variety of consumer activities within capitalist economic systems. His approach is a response to Marxist forms of critique that tend to focus on the dialectic relationship between the consumption and production. Certeau suggests that 
individuals frequently blur this distinction through appropriations of institutional operations called 'tactics.' One of these tactics is known as la perruque - translated as 'the wig' -- a practice that de Certeau describes as "the worker's own work disguised as work for his employer" (1984, p. 25). Masquerading as legitimate activity, la perruque allows the worker to divert time towards personal, creative means. Not overtly subversive, and refraining from destruction and theft, la perruque temporarily defers the authority of the employer, shifting the hierarchy of the institution. The 'work' produced -- although resembling that authorized by the company -- is truly owned by the employee. In identifying this activity as a tactic, de Certeau sees it as distinct from what he terms a 'strategy:' "A strategy assumes a place that can be circumscribed as proper and thus serves as the basis for generating relations with an exterior distinct from it. . . Political, economic, and scientific rationality has been constructed on this strategic model" (1984, p. 19).

Based on the writings of Benjamin and Certeau, I propose that the network society represents entirely new forms of interaction, allowing for tactics that emphasize new forms of visuality and that shift the producer/consumer binary. Along similar lines, New Media theorist Peter Lunenfeld (2000) argues that networked digital technologies actually dissolve the distinction between producer and consumer, in a decidedly post-Marxist manner. The network society that Castells (1996) describes is one that is shaped both by these massive institutional structures as well as the critical tactics of individuals. While the discussion of the possibilities for forms of pedagogy that address visual culture have done much to create critical dialogue and debate in the field of art education, the social impact of the digital simulation of images has not adequately been discussed.

In order to explore the possibilities for network forms of curriculum and practice in art education, I will briefly discuss examples from recent art educational literature that point towards the relevance of such models. 


\section{The Lattice and the Network}

In The Spiral and The Lattice: Changes in Cognitive Learning Theory with Implications for Art Education (1995), art educator Arthur Efland describes the general relationship between content and methodology in art educational practice:

It is assumed that certain arrangements of knowledge will enhance learning if, in some appropriate way, they are patterned after the structures of knowledge of the domain being taught, and that ultimately these structures enable learners to represent domain knowledge to themselves in flexible ways for effective application in relevant situations (p. 135)

In order to challenge the relevance of traditional art educational curricular models, Efland compares the spiral model of cognition discussed by Jerome Bruner in the 1960 's to a lattice-like structure represented by the hypertext curriculum proposed by Spiro, Coulson, Feltovich, and Anderson in 1988. He suggests that a lattice type model for curriculum might better represent the learning that takes place in the 'ill-structured domain' of art, based on Alexander's (1988) analysis of planned and unplanned cities.

There are many similarities between the lattice structures described by Efland and the structure of the Internet -- connections illuminated through the Gibson's (1984) 'constellations of data' and Castells' (1996) layers of flows. The lattice-like curriculum structure proposed by Efland begins to point towards a pedagogy that connects theory to practice, and, if substantially developed, may lead to a pedagogy that addresses the contemporary complexities of digital networks.

Art educator Karen Kiefer-Boyd (1997) suggests that experience with constructing hypertextual documents offer art educators the opportunity to make diverse connections in a manner similar to Efland's lattice. However, Kiefer-Boyd also fails to discuss the types of instructional changes that hypertext might necessitate. In fact, many art educators discussing the possibilities for the Internet in art classrooms do not inquire as to the intimate relationship 
between curriculum and pedagogy (Dunn, 1996, Heise and Grandgenett, 1996) - between what is taught and how this information is taught. This is a relationship that should be explored if art educators are to develop critical connections between developing technologies with wide-ranging social implications and contemporary forms of instruction.

If curricular structures were based on the model of the network - an expanded version of Efland's lattice -- the result might be a pedagogy that is adaptive to changing social, educational, and technological conditions. The integration of developing technologies within educational programs that are organized according to outdated modes of thought is problematic. It is, at the very least, very challenging for art educators to address the complexities of the current personal, social and aesthetic shifts related to networked digital technologies through practices based in previous pedagogies, simplified geometries, analog technologies.

As I have proposed, networked digital technologies such as the Internet are associated with multiple changes at many levels of society, changes that are both beneficial and restrictive. It is necessary to inquire as to the cultural and social implications that accompany such technologies as they relate to educational practice in general. The need for such inquiry is particularly necessary in art educational spaces, as the simplicity and the seductiveness of digital technologies - the increasing ease of connectivity and the availability of information offered by the Internet - may distract educators from questioning the potential for critical application. Critiquing the ideologies that underlie digital technologies as they are increasingly implemented in classrooms is crucial for an art education that is socially responsible, culturally relevant, and critically oriented. Failure to do so would reinforce preexisting power structures creating connections that restrict rather than instruct.

In order to present possibilities for practice that responds to and remains relevant within the network society I will present a brief overview of Castells' 'layers of flow,' which he describes in The Rise of the Network Society (1996). These layers of flow begin to map the structure of the network society, and have provided a theoretical structure for my developing notion of a 'network 
aesthetic.' I will present this comparison in order to determine the possible benefits of conceiving of art educational spaces in terms of network structures.

\section{'Layers of Flow' and Network Aesthetics}

As Castells (1996) describes, the first layer of flow is the physical basis for the network society: "The first layer, the first material support of the space of flows, is actually constituted by a circuit of electronic exchanges" (p. 442). This network is the technological infrastructure that allows for exchanges of information to take place. This layer can easily be seen in the structure of the Internet, as it continues to grow from preexisting telecommunications networks.

The second layer of flow is composed of the nodes and hubs that help to distribute information within the network. Nodes and hubs are created by the idiosyncratic flows of information within networks, modifying the existing materiality through active exchange. While nodes and hubs are established according to preexisting hierarchies, Castells (1996) states that these aspects of the network are not static: "This hierarchy may shift depending on the evolution of activities processed through the network" (p. 440). He indicates once again that initial networks evolve according to the operations of the users, similar to his description of the second level of flow (1999).

The third layer of flow relates to the power of the individuals that use the network: "... the spatial organization of the managerial elite" (p. 445). This layer indicates the presence of institutional power within networks, often connected to the ownership of the material infrastructure. The Internet -- for all of the utopian rhetoric associated with equality, racial blindness and participatory democracy -- is described in a bleak manner by Castells as another offshoot of global hypercapitalism. However, the structure of the Internet - the relationship between its materiality, forms of interaction, and potential for various flows of power - leads to the possibility for new forms of flow to emerge, for individuals to combine energies and redistribute power along alternate paths. 
The combination of a material infrastructure that is decentralized, layered with the ability for a vast range of users to actively modify the informational flows within the network has created an Internet that is almost impossible to manage. The interplay between top-down, institutional management and bottom-up, individualized redirections of power are crucial aspects of an Internet that exhibits the potential for both oppression and empowerment. The layers of flow that form the network society might be used to describe aesthetic gestures that reflect an understanding of the almost 'unthinkable complexities' of our age.

As I will explore in further writings, the notion of a 'network aesthetics' might be derived from the interplay between materiality, interaction, and power within the spaces of art educational practice. Acknowledging the relevance of this unique contemporary sensibility will allow educators to better understand a wide range of products of a digital visual culture - from student projects to artist works to activist tactics to elements of consumer culture. I have found in my research that a specific sensibility related to the network is reflected in work that combines open-ended treatments of these layers.

These works that I feel represent this 'network aesthetic' present an adaptable material structure with various possibilities for interaction, resulting in work that decenters form of power, challenging art historical notions of authenticity, authorship, and authority. The material structures varied widely in the works studied. One student created complex networks of ribbons that connected students to a dysfunctional keyboard, creating a visual analogue of the Internet. Other examples use the Internet itself, allowing the viewer/participant to adjust the work itself, modifying the parameters of the project, as in the 1994 Ping Body performance by Australian performance artist Stelarc.

The methods of interacting with the material aspects of such works are multiple and open-ended, typically allowing the viewer to manipulate elements. The network ribbon project described above acted as both metaphor for the complexity if the Internet, while allowing individuals to reflect upon and modify their method of communication. Better yet, the work might 
allow the viewer/participant to challenge the division between the artist and the audience, as in the performances of the Surveillance Camera Players (Sweeny, 2004)

The ability to adjust both the materiality and the ways in which these elements are used results in a form of power that is decentralized, that challenges the traditional authority of the artist, the artwork, and the art institution. The potential applications for this network aesthetics are numerous. Art educators might find the opportunity to discuss a variety of works in a new way, in a manner that relates to current social developments. Art students might recognize the existence of tactical adaptations related to digital technologies already in use, and find potential for the incorporation of such tactics within their work. Art education students might recognize similar tactics from their everyday lives, allowing them the opportunity to make connections between their own experiences and those of their students.

Acknowledging the varied and substantial implications of the network society will allow art educators to address contemporary issues related to the critical use of digital technologies in the spaces of art education. Perhaps more importantly, it will allow art educators to respond to the 'unthinkable complexity' of contemporary visual culture -making it thinkable through actively participation in the creation of new forms of visuality related to everyday life in the network society. 


\section{Bibliography}

Alexander, C. (1988) A city is not a tree. In J. Thakara (Ed.), Design after modernism: Beyond the object (p. 67-84). New York, NY. Thames and Hudson.

Benjamin, W. (1968). The work of art in the age of mechanical reproduction. In $\mathrm{H}$. Arendt (Ed.) Illuminations (H. Arendt, Trans.). New York: Schocken. (Original work published 1955)

Bukatman, S. (2000). Terminal penetration. In D. Bell and B. Kennedy (Eds.) The Cybercultures Reader. (p. 149-174). New York, NY. Routledge.

Castells, M. (1996). The rise of the network society. Malden, MA: Blackwell.

Castells, M. (1999). Flows, networks, and identities: A critical theory of the informational society. In M. Castells (Ed.) Critical education in the new information age (p. 37-64). Lanham, MD. Rowman \& Littlefield. California.

Certeau, M. D. (1984). The practice of everyday life. (S. Rendall, Trans.) Berkely, CA:

Clark, G. A., Day, M. D., \& Greer, W. D. (1989). Discipline-based art education: Becoming students of art. In R. Smith (Ed.). Discipline-based art education: Origins, meaning, and development. Urbana: University of Illinois Press (originally published 1987).

Dunn, P. (1996, November). More power: Integrated interactive technology and art education. The journal of the national art education association (54). 6-11.

Duncum, P. (2002a). Theorizing everyday aesthetic experience with contemporary visual culture. Visual Arts Research,28 (2), 4-15.

Duncum, P. (2002b). Wrestling with tv "rasslin." The Journal for Social Theory in Art Education, 22, 103-119.

Efland. A. (1995). The spiral and the lattice: Changes in cognitive learning theory with implications for art education. Studies in art education. 36 (3). 134-153.

Freedman, K. and Schuler, K. (2002) Please stand by for this important message: Television in art education. Visual Arts Research $28(2), 16-26$.

Gibson, W. (1984) Neuromancer. New York, NY. Ace Books

Heise, D. and Grangenett, N. (1996, November). Perspectives on the use of internet in art classrooms. The journal of the national art education association (54). 12-18.

Kiefer-Boyd, K. (1996). Interfacing hypermedia and the Internet with critical inquiry in the arts: Preservice training. The journal of the national art education association (54). 33-41.

Kiefer-Boyd, K. (1997). Interactive hyperdocuments: Implications for art criticism in a postmodern era. In J. Hutchens M. Suggs (Eds.) Art education: Content and practice in a postmodern era. (p. 122-131). Reston, VA: NAEA. 
Krug, D. (2002) Electronic media and everyday aesthetics of simulation. Visual Arts Research $(28,2)$. (p. 27-37).

Lunenfeld, P. (2000). Snap to grid: A users quide to digital arts, media, and cultures. Cambridge, MA: MIT Press.

Manovich, L. (2001) The language of new media. Cambridge, Mass: MIT Press.

Mirzoeff, N. (1998). What is visual culture? In N. Mirzoeff (Ed.), The visual culture reader. (p. 3-13). New York: Routledge.

Nichols, B. (1992) The work of culture in the age of cybernetic systems. In T. Druckery (Ed.) Electronic Culture (p. 121-143). Cambridge, MA: MIT Press.

Prater, M. (2001, November). Constructivism and technology in art education. The Journal of the National Art Education Association (54). 43-48.

Stockroki, M. (2002). Shopping malls from preteen and teenage perspectives. Visual Arts Research $28(2), 77-85$.

Tavin, K. (2002) Engaging advertisements: Looking for meaning in and through art education. Visual Arts Research 28 (2), 38-47.

Tavin, K. (2003) Wrestling with angels, searching for ghosts: Toward a critical pedagogy of visual culture. Studies in Art Education $44(3), 197-213$.

Taylor, P. and Carpenter, S. (2002, July). Inventively linking: Teaching and learning with computer hypertext. The Journal of the National Art Education Association 55 (4). 6-12.

Tomas, D. The technophilic body: On technicity in william gibson's cyborg culture. In D. Bell and B. Kennedy (Eds.) The Cybercultures Reader. (p. 175-189). New York, NY. Routledge. Touchstone.

Turkle, S. (1995). Life on the screen: Identity in the age of the internet. New York: 